\title{
The Construction of Multimodal ESP Network Teaching Platform via IM
}

\author{
Dongyan $\mathrm{Li}^{1, \text { a }}$, Qingfeng $\mathrm{Guo}^{2, \mathrm{~b}}$ * \\ ${ }^{1}$ College of Humanities and Social Sciences, Hei Longjiang Bayi Agricultural University, Daqing, Hei \\ Longjiang 163319, China; \\ ${ }^{2}$ College of Information Technology and Sciences, Hei Longjiang Bayi Agricultural University, Daqing, \\ Hei Longjiang 163319, China. \\ aredsun_2002@163.com, bgqfdfg@126.com
}

Keywords: Autonomous learning; constructivism; English for specific purposes; instant messaging; multimodal discourse analysis.

\begin{abstract}
Based on the multimodal discourse analysis theory and constructivist learning theory, the paper embarks from the English teaching of ESP (English for specific purposes) professional and comes to the conclusion that IM ( instant messaging) software is not only the physical tool of interactive communication,but embodies the spirit of win-win cooperation and sharing with people also by exploring the theoretical basis, the realization path and the design of the IM multimodal network teaching platform.
\end{abstract}

\section{Introduction}

The network teaching platform of the IM (instant messaging) software is typical of being open, collaborative, interactive, convenient, beyond time and space, providing more dynamic support for teaching, which is today the new paradigm adopted by a lot of teachers in universities for talent cultivation under the network environment and to a great extent can make up for the professional English class teaching time and space, and the lack of human interaction.

\section{Review of Relevant Theories}

English for Specific Purposes, or ESP, refers to a Specific profession or discipline related English, which is set according to learners' specific purpose and the specific in English courses [1].

At present, English teaching for special purposes (ESP) in domestic universities puts much emphasis on the acquisition of vocabulary, discourse structure, style, communication strategies and skills cultivation concerning a specific subject such as computer English, medical English, legal English [2], and its purpose is to cultivate students' communication ability in a certain work environment to use English. This is highly consistent with the idea held by some scholars from academic circles regarding the new positioning of college English, that is, the professional training of college students in English learning and application ability can improve students' professional English use in the field of international competitiveness and the competitiveness in related study or work in the future.

Particular social cultural background tends to breed and generate the teaching theory with which that echoes; multimodal ESP in terms of the theoretical basis of the construction of the network teaching platform mainly involves the following two aspects.

\subsection{Multimodal Discourse Analysis.}

The Web 2. 0 era of Internet interaction means the fast lane education informatization had entered with the digital teaching platform emerging one after another based on Internet technology.

Relatively, IM (instant messaging) software is multimodal which is characterized as text, voice, image and video and so many kinds of ideographic symbols with synchronous and asynchronous messaging and feedback, file transfer and sharing, multiple voice and video conversation, preservation and reproduction of record, etc.. The theory is that the use of multiple network resources 
such as images, video and other symbols can fully arouse the various senses of learners like vision, hearing, touch and so on [3]; the use of verbal and nonverbal medium provide relatively real communicative context for learners; as auxiliary means, symbols such as sound, video resources can stimulate the enthusiasm of learners to participate in communication and enthusiasm, so as to achieve an ideal communicative effect [4], which has a lot to do with the core idea of constructivism learning theory.

The constructivism believes that learning is an initiative building process, in which students do not passively accept outside information, but actively and selectively perceive external world according to the previous cognitive structure [5].

\subsection{Constructivism Learning Theory.}

Constructivism learning theory claims that four factors influence the learning process [6]. The first is "the learners as the center", in which constructivists believe learners are the body of cognition and actively construct knowledge; teachers change from the controllers into the facilitators of learners' meaning construction.

The second is the importance of the "situation", because it can arouse learners' association and they use the past experience to establish a link between the old and new knowledge by constructing new knowledge of the specific meaning through the profound understanding. The third is "cooperative learning”, which benefits a lot throughout the course of the learning process of learning from sorting out and analyzing information, asking questions and learning, evaluating learning effect and significance of the final construction, playing an irreplaceable role. The fourth is the design of learning environment, which will be regarded as the root of learners' discovery learning and exploratory learning through the use of a variety of learning tools and information resources to achieve the desired learning objectives.

Here when it comes to the multimodal resources, information resources as mentioned earlier, constructivism is a very appropriate with multimodal discourse analysis theory and they complement each other. In brief, under the background of the network environment the rich resources and the modal characteristics along with them help learners to mobilize all social resources and participation information such as images, text, sound for communication, interaction, meaning negotiation and construction. In specific to ESP teaching, college English teachers can use multiple modal theory and constructivist learning theory to build instant messaging software based on IM network platform, extending the limitations from traditional English teaching textbook knowledge, class time and space to interpersonal interaction of rich knowledge, real-time synchronous or asynchronous interaction outside of the classroom without being limited by space and time.

Teachers and students truly depend on the multimodal network resources based on the network platform, select teaching contents, teaching methods and strategies for effective teaching, thus stimulating the subjective consciousness from teachers and students, initiatively regulating self-recognition and behavior to achieve the purpose of raising the efficiency in English teaching and learning.

\section{The Design and its Implementation of Multimodal ESP IM Platform}

\subsection{The Selection of IM Software.}

In China, QQ owns the largest and most popular population among Chinese netizens of all the free IM software based on Internet along with QQ online chat, video phone, voice conference for many people, point to point or breakpoint files transmission, sharing files, network hard disk, custom panel, QQ, E-mail and other functions, which can be connected to a variety of communication methods like mobile communication terminal and so on. According to official statistics [7], more than two hundred million users in 2014 were online at the same time, covering almost all Chinese Internet users. Tencent QQ group can invite friends or people with common interests to a chat in the interface; users can use BBS, photo albums, file sharing, video and voice chat, etc. for a variety of ways to communicate with each other. The interface of QQ group is powerful, concise and easy to use, zero 
cost and presents a significant multimodal discourse. Therefore, we chose to use QQ group to build the multimodal ESP network teaching platform via IM.

\subsection{The Design of Multimodal ESP Platform via IM.}

The multimodal ESP platform via IM, namely, QQ group, is based on the theory of constructivism and meets the demand of professional English teaching design, integrating information release, online courses, learning resources, teaching resources, community communication and teaching management into one comprehensive platform. The platform has the characteristics of multimodal interaction, providing text, voice, image, video and other multimodal learning environment for students to obtain related knowledge and information in particular of knowledge acquisition, collaboration, communication, exploratory learning, which also plays a positive role in teaching and assessment.

There are six modules altogether. The Information module mainly includes ESP teaching syllabus, the subject of unit teaching objectives and tasks and information release with the mode of text given priority to; the Online Course module is used to play audio and video materials relevant to the subject matter and ESP teaching with the mode of sound given priority to; module Learning Resources provides extension information beyond textbooks, the reference answer, learning materials like educational courseware with the modes of words and images given priority to; module Teaching Resources covers ESP English vocabulary, syntax, discourse teaching and acquisition strategy in training content with the modes of text, images and sounds given priority to; module Community supplies ESP unit teaching topic, through online communication, BBS, discussion groups and synchronous or asynchronous communication such as QQ space with the modes of words, images, voice and expression, and other symbols modal given priority to; the Teaching Management module with the mode of text given priority to may blend management of members, operation management, resource management, and other functions into an organic whole and a few excellent students are invited to participate in ESP curriculum management who are responsible for establishing, releasing and sharing ESP related information resources, assisting teachers more effectively to realize the supervision and guidance of students' autonomous learning process.

Constructivism theory underpins the use during the whole process of multimodal ESP platform, which is helpful to build a sound learner-acquisition-and-internalization environment for ESP teaching and learning. In particular, teachers and students, students and students through QQ group can realize online group discussion, resource sharing, sharing communication; students can also know according to their own rate of progress language proficiency, knowledge accumulation and adjustment of professional English language acquisition and language use strategies. Professional English teachers and learners at higher levels in the process can provide correct and reasonable guidance for learners at lower levels, understanding learners' learning experience in ESP curriculum and process assessment so as to adjust the teaching content, difficulty, progress and teaching methods in time.

In addition, in the process of using the multimodal ESP teaching platform, teachers had better take into account the characteristics of students and the professional quality, engaging learners in an active state of mind to participate in the communication process to mobilize all kinds of verbal and nonverbal, namely, multimodal resources for the exchange and the construction of meaning in order to achieve the goal of the communication relevant to the subject matter and ESP teaching.

\subsection{The Realization of Multimodal ESP Teaching Platform via QQ Group.}

Group managers (teachers) create the QQ group according to the actual need and appoint several administrators (monitor or any other volunteer) to assist the resource construction and communication within members for various activities. After the login, the home page contains the "member list" in which administrators can be set. The following task is to invite students to join the group; in order to facilitate communication and performance evaluation, students are advised to modify group CARDS and enter in the form of "name plus class". Teachers post multimodal ESP teaching resources such as text, images, audio, video, stimulating students to build multimodal 
learning resources and regularly participate in workshops and exchange ideas for autonomous learning and collaborative learning. Multimodal assessment refers to the fact that teachers can online correct homework, try to create a variety of tests, build question bank; students can submit a job online, and check it. Teachers can according to the specific situation put forward concrete suggestions for further study. Keeping records of process evaluation is to help ensure the reliability and validity of the ESP teaching evaluation combined with summative evaluation.

\section{Conclusion}

The instant messaging software is not only a tool to build ESP teaching platform, but creates the multimodal network teaching environment under the guidance of constructivism theory through more exploration and cooperation, communication and common construction.

The instant messaging software is selected as the multimodal network teaching platform and the collaborative characteristics of network education are reflected; learners may well be provided with colorful, interactive, personalized autonomous learning platform without being limited by the time and space; teachers are inspired to be deeply involved in interaction and sharing teaching resources with students, which renders students' subjectivity to a greater development.

Also, the teaching platform needs the constant update and perfection in education practice according to the actual situation of ESP teaching and learning demand, in the hope of better serving the multimodal ESP teaching in the network environment.

\section{References}

[1] Hutchinson T, Water A. English for Specific Purposes. Cambridge University Press, 1987.

[2] Jigang Cai, Ningyang Chen. Needs analysis of English for special purposes under the background of internationalization of higher education. Computer-Assisted Foreign Language Education, Vol. 9 (2013) No. 153, p7-9.

[3] Yun Zhang. Computer Network-assisted Multimode Teaching in British and American Literature. Computer-Assisted Foreign Language Education, Vol. 3 (2012) No. 144, p65-68.

[4] Jianqing Huang. Study of network-based multi-modal college English writing teaching. Journal of Nanchang College of Education, Vol. 26 (2011) No.11, p161-162.

[5] Jianlin Chen. College English Curriculum Requirements: A Theoretical Understanding and Application. Media in Foreign Language Instruction, Vol. 3 (2004) No.100, p46-50.

[6] Zhihong Qi: The practical exploration of the integration of multimedia technology with vocational English teaching (Dissertation, Capital Normal University, China, 2008). p17-21.

[7] Information on: www.199it.com/archives/209314.html 